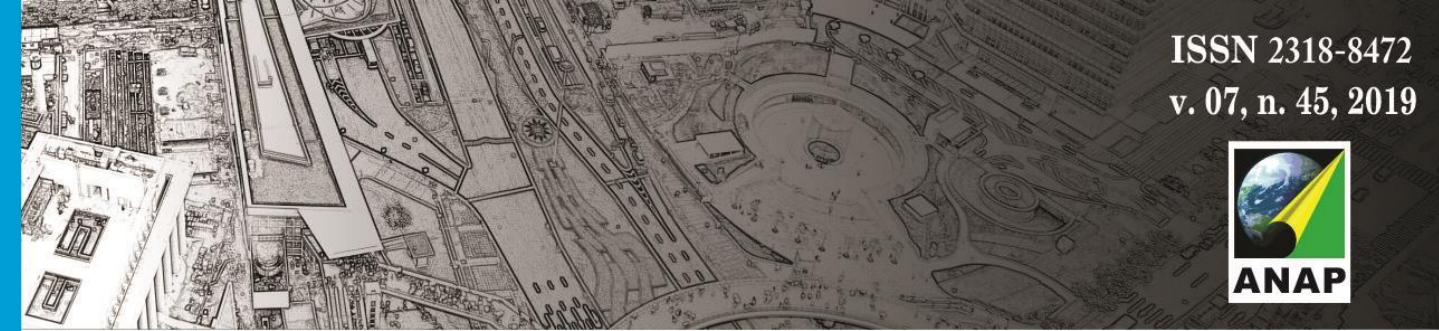

Revista Nacional de

Gerenciamento de Cidades

\title{
Análise temporal da incompatibilidade das Áreas de Preservação Permanentes fluviais e uso da terra na cidade Manaus- Amazonas- Brasil
}

Temporal analysis of the incompatibility of the Fluvial Permanent Preservation Areas and land use in the city Manaus- Amazonas- Brazil

Análisis temporal de la incompatibilidad de las Áreas de Preservación Permanentes fluviales y uso de la tierra en la ciudad Manaus-Amazonas- Brasil

João Cândido André da Silva Neto

Professor Doutor, UFAM, Brasil joaokandido@yahoo.com.br

\section{Natacha Cíntia Regina Aleixo \\ Professora Doutora, UFAM, Brasil joaokandido@yahoo.com.br}





\section{Revista Nacional de}

Gerenciamento de Cidades

\section{INTRODUÇÃO}

A relação entre sociedade e natureza ocorre de maneira distinta, normalmente distinta, normalmente numa relação é desigual e conflituosa, como todo processo de apropriação da natureza no espaço urbano.

O processo contemporâneo de urbanização é caracterizado com a mais intensa amostras das transfigurações das paisagens no espaço urbano, consequentemente caracterizando-se pelas alterações nas dinâmicas e processos das paisagens naturais podendo desencadear diversos impactos ambientais nessas áreas.

Esse processo de implantação e expansão dos sítios urbanos acarretam os mais distintos impactos que podem ser observados na interface sociedade natureza, pois se têm como resultados desses impactos a poluição, a inundação, a natureza, atingem diretamente a sociedades que ocupam essas áreas vulneráveis.

Para Gonçalves e Guerra (2004), as cidades constituem hoje o maior exemplo de degradação ambiental, colocando em risco a segurança e a quantidade de vida de sua população, constituindo um palco de embates ecológicos.

Enfatiza-se que o impacto da urbanização pode ocorrer sobre a quantidade de água, sedimentos e qualidade da água, e o controle desses impactos pode atender a um ou mais desses problemas. Segundo Silva et al. (2007) os problemas de qualidade/ quantidade de água são intensificados pelo desenvolvimento urbano, no qual a cobertura vegetal é muitas vezes destruídas durante as construções e substituída por prédios e ruas. Com isso observa-se a redução da infiltração e aumento do escoamento superficial.

Dentre os problemas ambientais resultantes do processo de urbanização, pode-se enfatizar o aumento do volume de água no escoamento superficial, que resulta em aumento dos níveis de águas dos rios e riachos, acarretando inundações de áreas que anteriormente não eram inundadas (BEASLEY, 1972 apud SILVA et al. 2007).

Coelho (2004) considerou que a urbanização consiste em uma transformação da sociedade, e os impactos ambientais promovidos pelas aglomerações urbanas são ao mesmo tempo, produto e processo de transformações dinâmicas e reciprocas da natureza e da sociedade estruturada em classes sociais.

Os problemas ambientais nas cidades brasileiras estão diretamente associados à gênese do processo de urbanização, cuja ocupação espontânea e desordenada é considerada como um dos principais problemas de ordem socioambiental que atingem as populações urbanas.

Os problemas ambientais urbanos estão diretamente associados ao processo de segregação social, visto que recorrentemente as áreas problemáticas do ponto de vista da ocupação desordenada, ocorrem devido à busca por áreas com preços abaixo dos praticados pelo mercado imobiliário, o que nem sempre apresentam condições favoráveis para sua ocupação, pelo contrário, caracterizam-se pela ausência de serviços de saneamento básico e infraestrutura. 


\section{Revista Nacional de}

Gerenciamento de Cidades

Nesse sentido, as Áreas de Preservação Permanentes (APPs) são definidas segundo o Código Florestal Brasileiro, Lei $\mathrm{N}^{\circ}$ 12.651, instituída em 25 de maio de 2012, em que a Área de Preservação Permanente (APP) é definida como "área protegida, coberta ou não por vegetação nativa, com a função ambiental de preservar os recursos hídricos, a paisagem, a estabilidade geológica e a biodiversidade, facilitar o fluxo gênico de fauna e flora, proteger o solo e assegurar o bem-estar das populações humanas" (BRASIL, 2012).

O processo de ocupação urbana muitas vezes ocorre de maneira espontânea em que se verifica ocupações por habitações em áreas inadequadas onde não são respeitadas as limitações de usos desses ambientes.

Assim alterações causadas pela atuação antrópica na paisagem, devem ser vistas como principal transformadora das condições ambientais, podendo modificar o modo como atuam as dinâmicas naturais ou desencadear a intensificação dos processos, podendo levar a uma situação de impacto ambiental.

Assim, as Áreas de Preservação Permanentes (APPs) devem ser entendidas como áreas prioritárias do ponto de vista da conservação ambiental, pois essas áreas estão diretamente ligadas à manutenção da recarga de mananciais, controlador das dinâmicas de escoamento superficial e infiltração e estabilização de vertentes.

Segundo Silva et al. (2007) a cobertura do solo é um fator que está fortemente ligado, além da dimensão ambiental, às dimensões econômicas, sociais e culturais de uma região, esses fatores em conjunto podem explicar o modo pela qual o solo de uma região vem sendo manejada de uma determinada forma.

A cobertura vegetal tem um papel importante na proteção da superfície dos solos, desse modo, quanto mais protegida por essa cobertura contra a ação da chuva, menor será nele a disposição para a ocorrência da erosão (PRUSKI, 2006).

Consequentemente, a retirada da cobertura vegetal, que funciona como uma proteção natural dos solos influenciará na intensificação da erosão, proporcionando ainda a incidência da radiação solar na superfície do solo, o que pode implicar na destruição da matéria orgânica do solo.

As APP's são destacadas como áreas que apresentam altos índice de fragilidade ambiental, em que estão mais suscetíveis ao desencadeamento de processo de degradação ambiental.

\section{OBJETIVOS}

\section{Geral:}

Analisar a incompatibilidade entre uso da terra e cobertura vegetal na área urbana da cidade de Manaus - AM.

\section{Específicos:}

Delimitar e mapear as Áreas de Preservação Permanentes (APPs) na área urbana da cidade de Manaus, conforme legislação vigente;

Mapear os tipos da terra na área estudada na cidade de Manaus entre os anos de 1987 e 2017; 


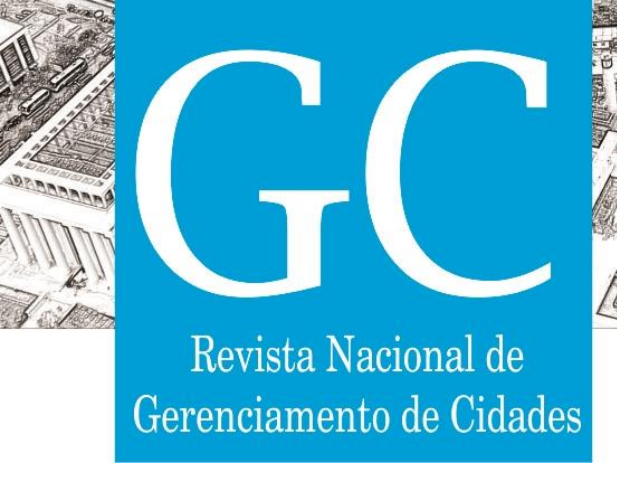

ISSN 2318-8472

Figura 3. Mapa das Áreas de Preservação Permanente fluviais de Manaus -AM

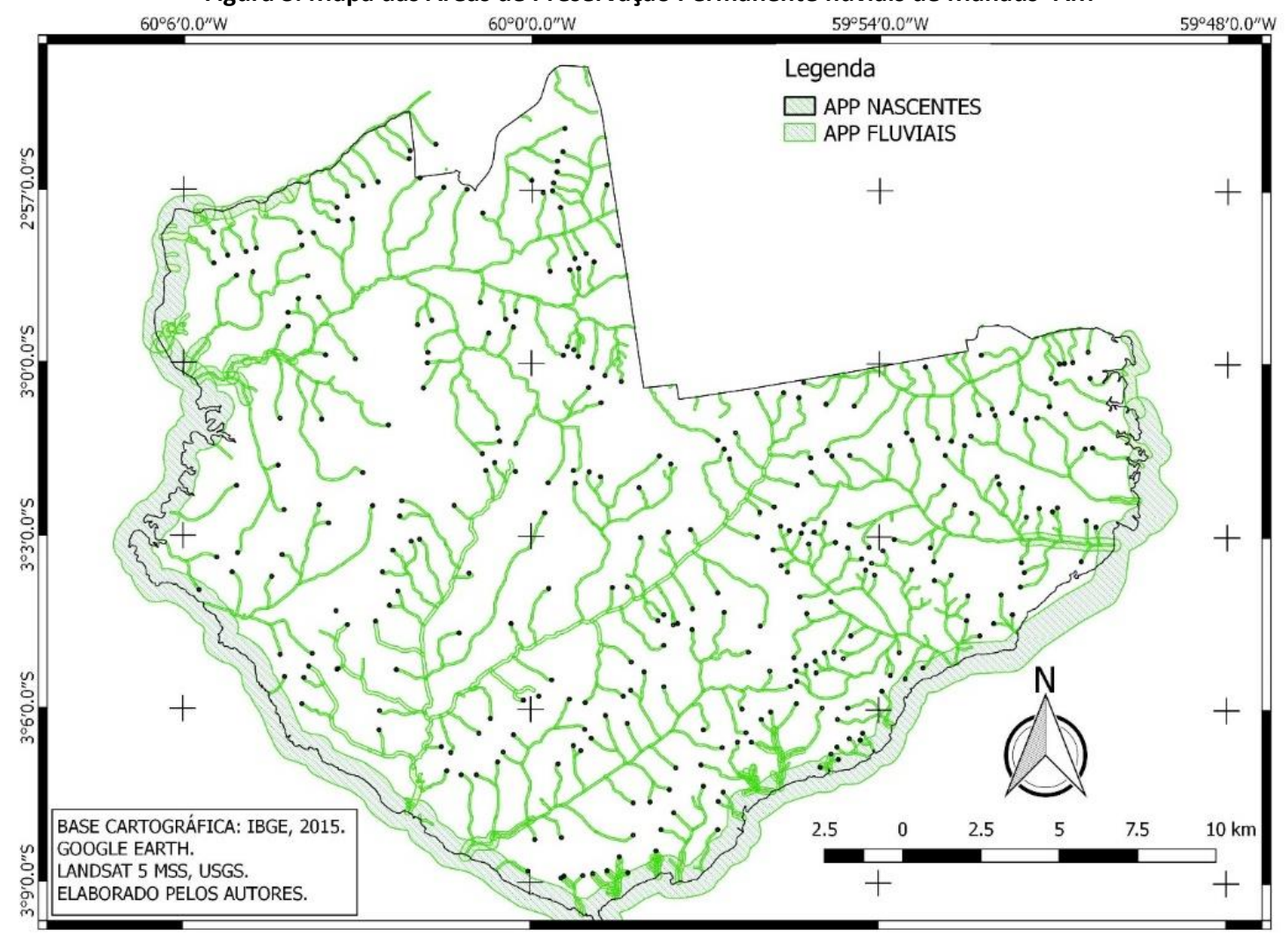

Elaborado pelos autores.

Quantos ao processamento de imagens de satélites para elaboração do uso da terra e cobertura vegetal, realizou-se download no site do Serviço Geológico Americano - USGS, para obtenção das imagens do Landsat 8 OLI (Operational Land Imager) do ano de 2017 e Landsat 5 MSS (MultiSpectral Scanner) do ano de 1987 (Quadro 1).

\begin{tabular}{|l|l|l|l|l|}
\hline \multicolumn{2}{|c|}{ Quadro 1: Imagens Landsat utilizadas. } \\
\hline Satélite/Sensor & Data & $\begin{array}{l}\text { Órbita/ } \\
\text { Ponto }\end{array}$ & Canais & $\begin{array}{l}\text { Resolução } \\
\text { Espacial }\end{array}$ \\
\hline Landsat-5-MSS & $12-07-1987$ & $231 / 62$ & 2,3 e 4 & $82 \mathrm{~m}$ \\
\hline Landsat-8-OLI & $30-07-2017$ & $231 / 62$ & 6,5 e 4 & $30 \mathrm{~m}$ \\
\hline
\end{tabular}

Após a aquisição das imagens de Landsat 8 OLI e $5 \mathrm{MSS}$, foi realizado o procedimento no software QGIS, para composição colorida canais do R-Vermelho, NIR - Infravermelho próximo e SWIR Infravermelho médio. 


\section{Revista Nacional de}

Gerenciamento de Cidades

A seleção das bandas se deram a partir das respostas espectrais dos alvos para mapeamento de uso da terra e cobertura vegetal, como corpos hídricos, solos exposto, vegetação sadia e desmatamento.

O passo seguinte foi o georeferenciamento e reprojeção da imagem, realizado no Software QGIS. Em seguida foi realizada importação da imagem no software SPRING, para que fossem realizados o processamento para classificação da imagem.

Após a importação da imagem, realizou-se a segmentação da imagem em que se agrupa a imagem em regiões com agrupamento de pixels semelhantes Entende-se por regiões, um conjunto de "pixels" contíguos, que se espalham bidirecionalmente e que apresentam uniformidade.

As etapas de classificação de imagem no software Spring foram: Treinamento corresponde à coleta de amostras (pixels coletados), a Classificação, é a etapa que as amostras são analisar em que é possível observar e corrigir as amostras que apresentam confusão e erro. Na etapa de classificação é possível estabelecer o limiar aceitável de erro, nesse caso foi de 99\%, e também selecionar o classificador, o utilizado foi o classificador supervisionado Bhattacharya.

A Pós-classificação é o estabelecimento de um limiar para eliminar ruídos, ou seja, pixels isolados decorrentes do processo de classificação.

O Mapeamento é a associação da imagem classificada com as classes temáticas estabelecidas no modelo de dados.

Após o processo de classificação de imagem, realizou a análise dos tipos de uso da terra com APP's, verificando-se assim as áreas de incompatibilidade entre essas duas variáveis, em que o uso da terra e cobertura vegetal foi definido em duas classes: as áreas Florestadas que corresponderia as áreas preservadas de vegetação primária, floresta e áreas verdes; e as áreas Desflorestadas, que corresponderia as áreas que foram desmatadas, áreas de solos exposto e área urbana construída.

\section{RESULTADOS}

A análise do uso do solo e cobertura vegetal dos anos de 1987 e 2017, possibilitou a visualização das transformações provocadas pela ocupação social da natureza na área urbana do município de Manaus-AM, em que é visível essas alterações antrópicas, que devem ser vistas como fundamental transformadora das dinâmicas ambientais.

Ao longo das últimas décadas tem se observado um representativo aumento populacional em Manaus, mais de um milhão de pessoas, que em parte está associado à implantação da Zona Franca de Manaus, e oferta de empregos para pessoas de outros municípios do Estado do Amazonas como de outras regiões do Brasil (Gráfico 1). 
Gráfico 1- População município de Manaus

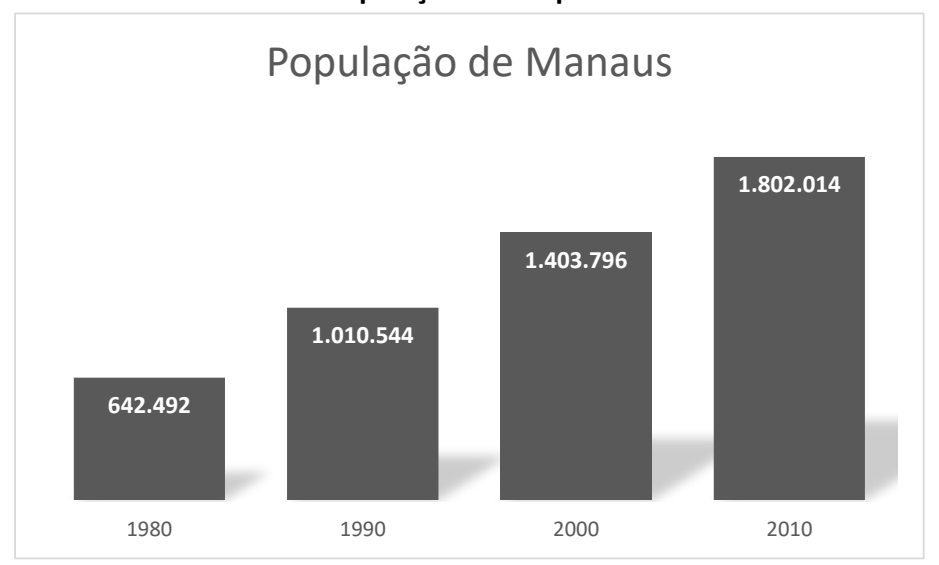

Fonte: IBGE: 2018.

O aumento das populações em grandes cidades, normalmente está associado a expansão urbana, implantação de novos loteamentos e habitações, que nem sempre respeita os condicionantes físicos-naturais das cidades, o que se tem observado de maneira geral nas grandes cidades brasileiras é um processo de ocupações inadequadas em fundos de vales, de áreas de risco à inundação e/ou deslizamento, canalização dos corpos hídricos e compactação do solo.

Assim, esse processo de apropriação e exploração da natureza acarretam problemas de ordem socioambiental, por ser prejudicial à natureza e sociedade, desencadeando processos erosivos, movimentos de massa, poluição e contaminação dos corpos hídricos, além estar associado aos problemas de saúde pública, como a ocorrência de doenças relacionada à água.

Nesse sentido, o processo de uso da terra, está diretamente ligado à apropriação da natureza, que muitas vezes não respeitam limitantes como as Áreas de preservação Permanente.

Assim o presente trabalho, mapeou o uso da terra e cobertura vegetal na área urbana de Manaus nos anos de 1987 e 2017, estabelecendo-se uma classificação, cujo objetivo foi identificar a incompatibilidade entre uso da terra e as APP's.

As classes de uso da terra e cobertura vegetal definidas com as áreas Florestadas que corresponderia as áreas preservadas de vegetação primária, floresta e áreas verdes, observouse a diminuição de 78\% da área urbana em 1987, para 52\% em 2017; e as áreas definidas como Desflorestadas, que corresponderia as áreas que foram desmatadas, áreas de solos exposto e área urbana construída, verificou-se o aumento de $22 \%$ da área urbana classificada com Desflorestada em 1987 para 44\% em 2017. (Figura 4 e 5). 


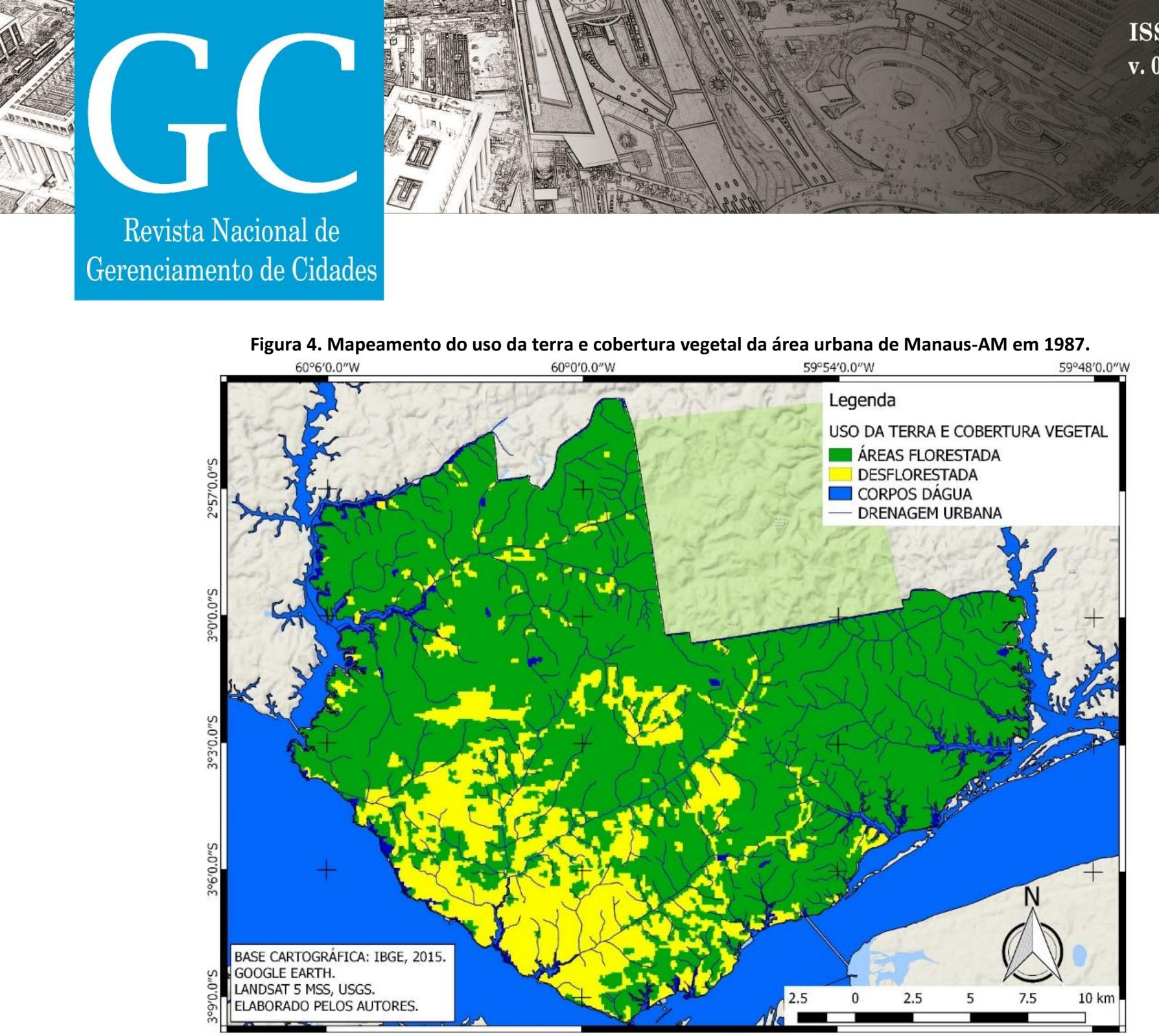

Organizado pelos autores.

As áreas de floresta correspondem as áreas de vegetação preservada, por sua vez a classe desflorestada agrupam as áreas com vegetação secundária de porte herbáceo e arbustivo, ou áreas utilizadas para outros fins com loteamentos irregulares e pastagem, observadas principalmente nas áreas periféricas da cidade de Manaus o solo exposto corresponde às áreas sem presença de vegetação e/ou área urbanizada e construída. 


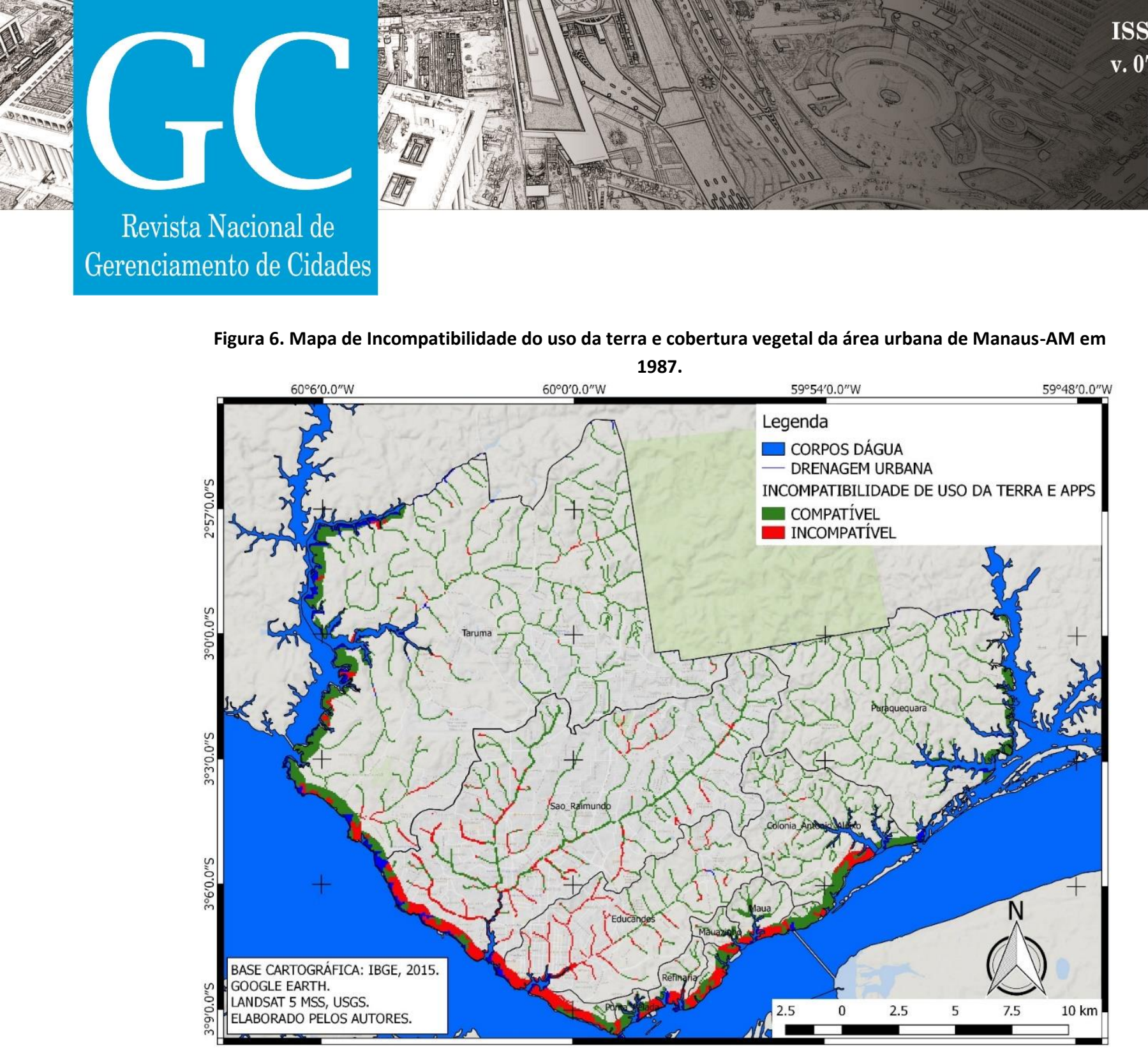

Organizado pelos autores.

Inversamente as Áreas de Preservação Permanente no ano de 1987 nas bacias hidrográfica como: Paraquequara, Colônia Antônio Aleixo, Mauá, Mauazinho e Tarumã apresentavam-se em conformidade à legislação vigente na época, predominando a compatibilidade em APP's as áreas Florestadas.

Desse modo, verificou-se que a Incompatibilidade entre uso da terra e Áreas de Preservação Permanentes, estão diretamente relacionadas às áreas densamente ocupadas ou ocupações irregulares, e sua distribuição espacial é verificada de modo mais intenso principalmente nas bacias hidrográficas do São Raimundo e Educandos.

Observou-se representativa Incompatibilidade entre uso da terra e Áreas de Preservação Permanentes nas porções do alto curso da bacia hidrográfica do São Raimundo, principalmente nas APP's fluviais localizadas em bairros como: Novo Aleixo, Cidade de Deus, São José, Tancredo Neves e Jorge Teixeira (Figura 7). 


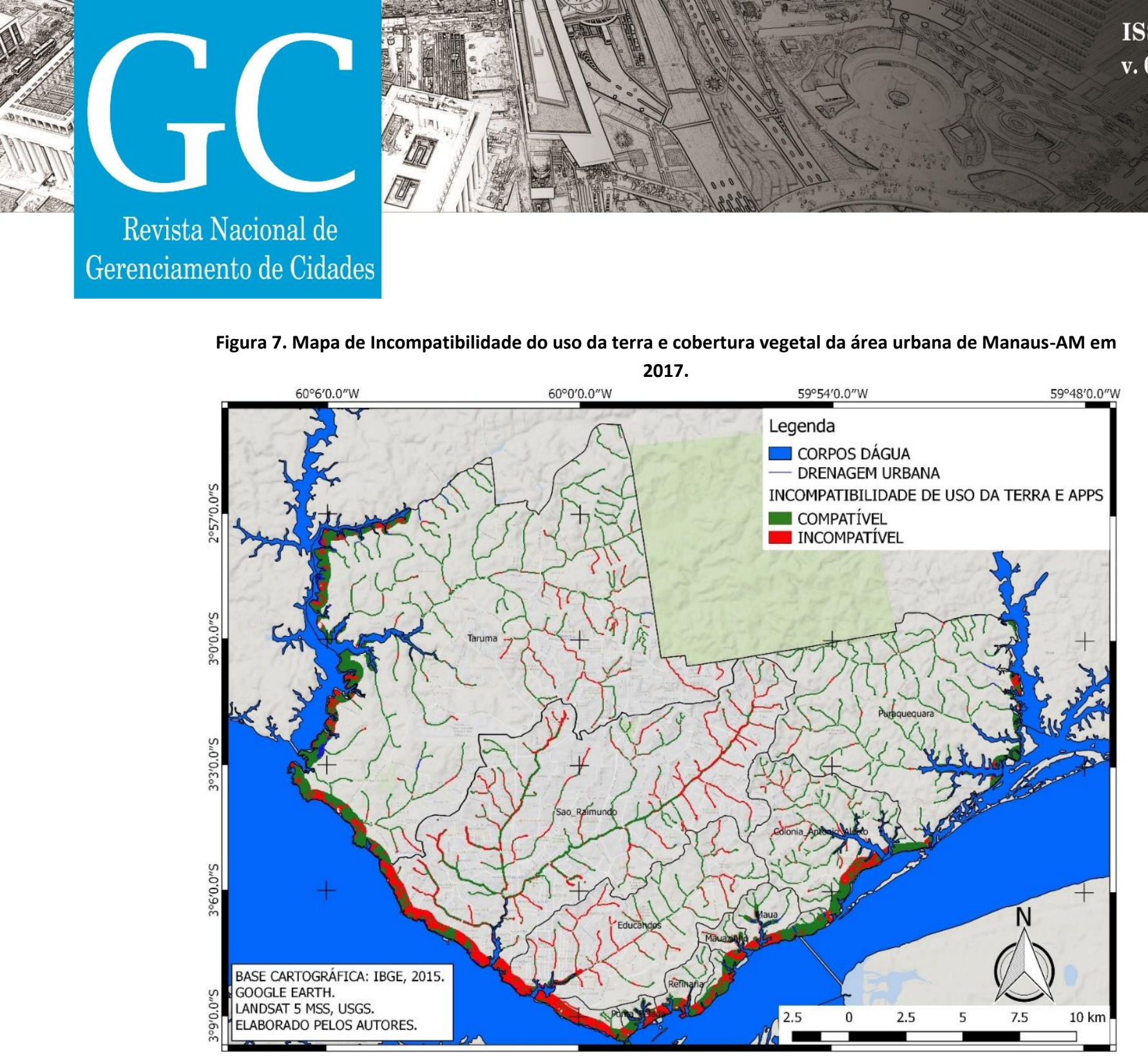

Organizado pelos autores.

$\mathrm{Na}$ bacia hidrográfica do Educandos a Incompatibilidade entre uso da terra e Áreas de Preservação Permanentes é observada de modo representativo nas porções do baixo curso da bacia, em que as Áreas de Preservação Permanente praticamente foram devastadas pelo processo de urbanização em bairros como Japiim, Petrópolis, Raiz, São Francisco, Crespo, Betânia, Centro e Educandos (Figura 8). 


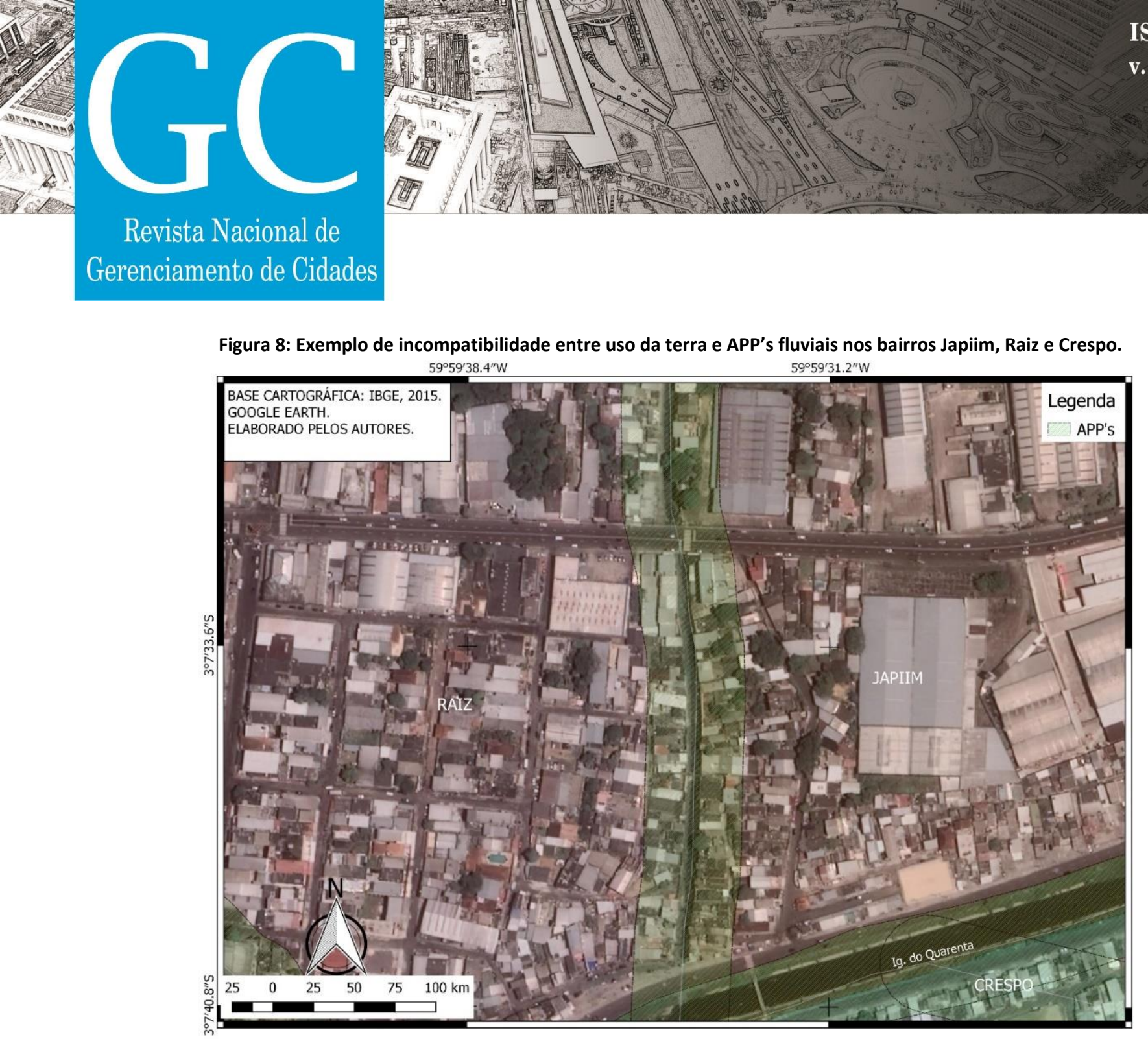

Figura 8: Exemplo de incompatibilidade entre uso da terra e APP's fluviais nos bairros Japiim, Raiz e Crespo.

Organizado pelos autores.

Quanto à temporalidade da Incompatibilidade entre uso da terra e cobertura vegetal e as Áreas de Preservação Permanentes, observou-se que em trinta anos, de 1987 a 2017, houve a diminuição das áreas florestadas, consequentemente o aumento de $26 \%$ para $33 \%$, de áreas que deveriam ser preservadas, porém, apresentam usos diversos e inadequados (Gráfico 2). 


\section{Revista Nacional de}

Gerenciamento de Cidades

Gráfico 2- Incompatibilidade entre APP's e uso da terra e cobertura vegetal da área urbana de Manaus-AM em 1987 e 2017.

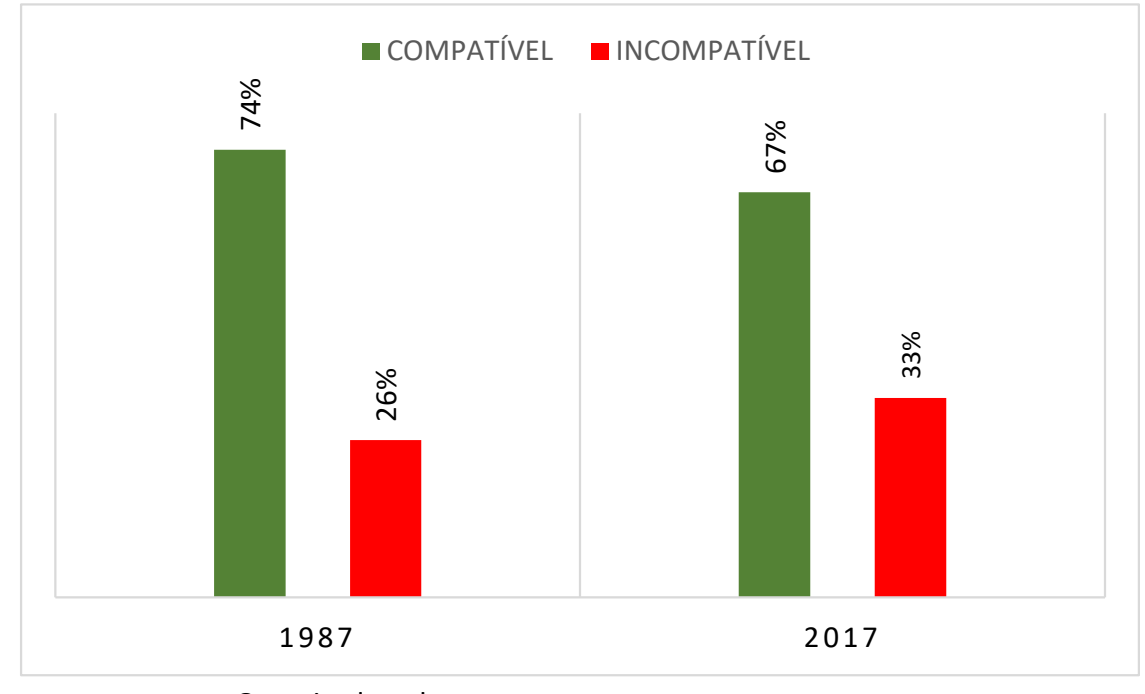

Organizado pelos autores

\section{CONCLUSÃO}

As áreas de florestadas representaram em 2017, 56\% da área de estudo, esse valor deve-se a presença de reservas florestais e parques no perímetro urbano da cidade de Manaus.

A cobertura vegetal tem um papel primordial na manutenção da biodiversidade, proteção dos solos e áreas de recarga de lençóis freáticos, assim, com a retirada da cobertura vegetal, esses ambientes se tornam mais vulneráveis aos impactos ambientes em diversas proporções.

As áreas de desmatamento e solo exposto, classificadas como desflorestadas, estão associadas à expansão urbana e ao crescimento populacional da cidade de Manaus nas últimas décadas, esse processo tem como consequência a ocorrência de diversos impactos ambientais, como poluição dos corpos hídricos, diminuição da biodiversidade local, aceleramento de processos erosivos, aumento das áreas de risco aos movimentos de massa.

Assim, os presentes resultados apontam para a importância da manutenção e recuperação das Áreas de Preservação Permanentes na cidade de Manaus, visto seu papel primordial na estabilização de ambientes frágeis, destacando-se ainda a importância das políticas públicas para voltadas para a questão ambiental de uma metrópole na Amazônia brasileira.

\section{REFERÊNCIAS BIBLIOGRÁFICAS}

BRASIL, Lei n 12.651, de 25 de maio de 2012. Diário Oficial da União, Poder Executivo, Brasília, DF, 28 de maio de 2012.

COELHO, M. C. N. Impactos Ambientais em Áreas Urbanas: teorias, conceitos e métodos de pesquisa. In: CUNHA, S. B.; GUERRA, A. J. T. (Org.); Impactos Ambientais Urbanos no Brasil. 2a Ed. Rio de Janeiro: Bertrand Brasil, 2004. 
